\title{
Pengaruh Sistem Hidroponik Dan Media Tanam Terhadap Pertumbuhan Dan Produksi Tanaman Kembang Kol (Brassica oleraceae)
}

\author{
Effect of Hydroponic System and Growing Media on Growth and Production of Cauliflower (Brassica \\ oleraceae).
}

\author{
Abdul Rofik \\ Tenaga Pendidik Program Studi Agroteknologi, Fakultas Pertanian, Universitas Widya Gama Mahakam \\ Jl. KH. Wahid Hasyim, Sempaja, Samarinda, Kalimantan Timur, Indonesia \\ email : birudaun83@gmail.com
}

Diterima : 5 Juni 2016 Disetujui : 23 Juni 2016

\begin{abstract}
Effect of Hydroponic System and Growing Media on Growth and Production of Cauliflower (Brassica oleraceae). Results of analysis of variance showed that the influence of the hydroponic system very significant effect on plant height $8 \mathrm{ABP}, 10 \mathrm{ABP}$. A high of $33.24 \mathrm{~cm}$ and $32.11 \mathrm{~cm}$ lows. number of leaves $8 \mathrm{ABP}, A B P 12$ with the highest value is 34.33 and the lowest 28.83. the flowering with the fastest value is 57.75 days and 76.50 days late, the diameter of the flower with the highest score is 71.32 grams and 64.05 grams lows. Hydroponic growing media influence a very significant effect on the number of leaves $4 A B P, A B P$, and 8 weeks after planting. Significant effect on plant height $2 A B P, A B P 6,8 A B P, A B P 12$ with the highest score is $33.26 \mathrm{~cm}$ and the lowest was 32.42 cm, number of leaves 2 MST, MST 12 with the highest score is 34.08 and the lowest strand 29, 83 strands, the flowering with the fastest value is 75.75 days and 84.42 days late, flower diameter highest score is $71.15 \mathrm{~mm}$ and $61.51 \mathrm{~mm}$ and the weight the lowest rate that is the highest value and the lowest 43.8253 .65 grams g.interaction hydroponic system and growing media very significant effect on plant height $6 \mathrm{ABP}$ with the highest value is 26.85 $\mathrm{cm}$ and $19.60 \mathrm{~cm}$ lows. Significant $2 \mathrm{ABP}, 8 \mathrm{ABP}, A B P 10, A B P 12$ with the highest score is $33.75 \mathrm{~cm}$ and the lowest was $31.15 \mathrm{~cm}$, number of leaves $2 \mathrm{ABP}, A B P 4,6 \mathrm{ABP}, 8 \mathrm{ABP}, A B P 10, A B P 12$ with the highest score namely lows of 40.50 and 27.00, the fastest flowering with a value that is 67.00 days and 87.25 days late and a diameter of flowers with the best value and the lowest is $72.39 \mathrm{~mm} 53.35 \mathrm{~mm}$.
\end{abstract}

Keywords : Hydroponic system, growing media and Cauliflower

\section{PENDAHULUAN}

Pertanian merupakan bidang prioritas dalam program pembangunan di Kalimantan Timur, dimana pemerintah Provinsi Kalimantan Timur akan menjadikan Provinsi Kalimantan Timur sebagai lumbung pangan di Indonesia. Untuk mewujudkan dan mendukung program tersebut Dinas Pertanian Tanaman Pangan Provinsi Kalimantan Timur akan terus mengupayakan peningkatan di bidang pertanian yaitu membudidayakan berbagai tanaman sayursayuran salah satunya adalah tanaman kembang kol. Rata- rata produksi kembang kol tahun 2014 adalah 43 ton/ha. Merupakan potensi yang cukup besar bagi perkembangan dan kemajuan hasil pertanian kalimtan timur (Anonim 2014 ${ }^{\mathrm{f}}$ )

Kembang kol merupakan tanaman sayur famili Brassicaceae (jenis kol dengan bunga putih kecil) berupa tumbuhan berbatang lunak. Masyarakat di Indonesia menyebut kubis bunga sebagai kol kembang atau blumkol (berasal dari bahasa Belanda Bloemkool). Tanaman ini berasal dari Eropa subtropis di daerah Mediterania. Kembang kol yang berwarna putih dengan massa bunga yang kompak seperti yang ditemukaan saat ini dikembangkan tahun 1866 oleh Mc. Mohan ahli benih dari Amerika. Kubis bunga diduga masuk ke Indonesia dari India pada abad ke XIX. Kembang kol termasuk dalam suku kubis-kubisan atau Brassicaceae. Kembang kol (Brassica oleracea. Subvar. Cauliflora DC) termasuk jenis sayur-sayuran dengan nilai ekonomi tinggi. Nilai jual kembang kol yang tinggi tak diiringi kuantitas produksinya.Tanaman kembang kol hinggasampai saat ini belum memberikan keuntungan kepada petani secara optimal karena jumlah kembang kol yang dapat dipanen jumlahnya sedikit (Rukmana, 1994).

Kembang kol memerlukan iklim khusus, yaitu udara yang dingin, air yang banyak dan lembab. Kehadiran hidroponik menambah ragam pertanian modern dalam menjawab berbagai permasalahan dalam sistem konvensional. Sistem budidaya hidroponik memungkinkan kita bercocok tanam tanpa tanah dan sangat memungkinkan diterapkan di dalam ruangan (indor). Keuntungan hidroponik diantaranya bersih, tanpa tergantung pada musim relatif bebas hama, perawatannya mudah, memiliki unsur dekoratif, dan bahkan dapat menjadi 
pilihan usaha agribisnis yang menguntungkan. Pasalnya, hidroponik mampu meningkatkan kepadatan tanaman persatuan luas dibandingkan sistem bertanam secara konvensionl. Bertanam sayuran dengan sistem hidroponik merupakan solusi pertanian yang sangat potensial untuk dikembangkan diwilayah perkotaan. hidroponik merupakan salah satu alternatif bagi para pehobi untuk mendekatkan pasar ke dapur yang artinya, kita tak perlu repot- repot lagi berbelanja ke pasar yang jaraknya cukup jauh dari rumah, dengan bertananam menggunakan sistem hidroponik kita bisa memanfaatkan lahan-lahan di pekarangan rumah untuk budidaya tanaman sayuran(Hendra dan Andoko, 2014).

Meningkatnya permintaan terhadap kembang kol, maka petani perlu mengimbangi dengan meningkatkan produksi serta kualitas. Untuk peningkatan produksi dan kualitas kembang kol, sudah tentu diperlukan benih yang baik dan sistem budidaya yang tepat dan sesuai serta perawatan yang tepat. Nutrisi yang dibutuhkan tanaman hidroponik pada dasarnya sama dengan tanaman yang dibudidayakan secara konvensional. Bertanam dengan sistem

\section{BAHAN DAN METODE}

Penelitian dilaksanakan selama 4 (empat) bulan, terhitung mulai bulan Juni 2015 sampai dengan bulan Oktober 2015. Lokasi penelitian terletak di Jl, Karpotek, blok MM No.7, Kelurahan Karang Asam Samarinda. Bahan yang digunakan yaitu ; benih kembang kol , Nurisi A dan B Good Plant, air, arang sekam arang dan cocopeat. Penelitian ini disusun dalam Rancangan Acak kelompok (RAK) dengan analisis faktorial $3 \times 3$ dan diulang sebanyak 4 (empat) kali. Perlakuan terdiri dari 2 (dua) faktor, yaitu : Faktor pertama adalah sistem konvensional, tanaman memperoleh nutrisi dari tanah tempatnya tumbuh. Sementara itu, pemberian pupuk pada sistem konvensional tersebut hanya sebagai tambahan karena tanah sudah mengandung garam-garam pupuk. Nutrisi hidroponik mutlak diberikan ke pada tanaman yang dibudidayakan secara hidroponik karena fungsi tanah dihilangkan dalam sistem ini. Bertanam secara hidroponik sangat membutuhkan jumlah pemberian nutrisi yang sesuai dengan kebutuhan tanaman yang ditanam. Sistem budidaya hidroponik juga sangat cocok untuk tanaman kembang kol (Anonim, 2014).

Media tambahan hidroponik yang berfungsi sebagai pemegang kelembapan maupunt empat akar berpijak lebih kuat yaitu media anam padat, media tanampadat dikelompokan menjadi media organikyaitu, pasir, vermikulit, eatmoss, kerikil, cocopet dan arangsekam kelbihan media organik antara lain kemampuan menyangga $\mathrm{pH}$ tinggi. Media non organik diantaranya adalah perlite, rockwool, dan clay granular keuntungannya adalah pertama kali digunakan keseterilan media non organik lebih terjamin dibandingkan media organik.(Anonim, 2014 ${ }^{\mathrm{c}}$ ).

hidroponik yang berbeda terdiri dari 3(tiga) taraf, yaitu : s1: Ebb and flow (pasang- surut), s2 : Drip irigasi(irigasi tetes) dan $\mathrm{s} 3$ : Wick system (sistem sumbu). Faktor kedua adalah media tanam yang berbeda terdiri dari 3 (tiga) taraf, yaitu : m1: Arang sekam, m2 : Cocopeat dan m3 :Arang sekam + Cocopeat. Data pengamatan yang diambil ; tinggi tanaman, jumlah daun, hari pertama berbunga, diameter bunga, dan berat bunga pertanaman. Data dianalisis dengan menggunakan sidik ragam, apabila terdapat pengaruh pada sidik ragam maka dilakukan uji BNT pada taraf $5 \%$ untuk membandingkan dua rata-rata perlakuan.

\section{HASIL DAN PEMBAHASAN}

\section{Pengaruh Media Tanam}

Tabel 1. Rata-rata tinggi tanaman $(\mathrm{cm})$ pada perlakuan media tanam

\begin{tabular}{ccccccc}
\hline \multirow{2}{*}{ Media tanam } & \multicolumn{7}{c}{ Umur tanaman (mst) } \\
\cline { 2 - 7 } & 2 & 4 & 6 & 8 & 10 & 12 \\
\hline m1 & $7,43 \mathrm{a}$ & $20,84 \mathrm{a}$ & $21,07 \mathrm{c}$ & $26,77 \mathrm{~b}$ & 30,01 & $33,26 \mathrm{a}$ \\
$\mathrm{m} 2$ & $6,49 \mathrm{~b}$ & $19,15 \mathrm{~b}$ & $22,45 \mathrm{~b}$ & $25,20 \mathrm{c}$ & 29,54 & $32,42 \mathrm{c}$ \\
$\mathrm{m} 3$ & $6,48 \mathrm{~b}$ & $17,58 \mathrm{c}$ & $23,18 \mathrm{a}$ & $28,15 \mathrm{a}$ & 32,89 & $32,48 \mathrm{~b}$
\end{tabular}

Keterangan : Angka-angka yang diikuti huruf yang sama menunjukkan tidak berbeda nyata pada uji BNT 5\% 
Tabel 2. Rata-rata jumlah daun (helai) pada perlakuan media tanam

\begin{tabular}{ccccccc}
\hline \multirow{2}{*}{ Media tanam } & \multicolumn{7}{c}{ Umur tanaman (mst) } \\
\cline { 2 - 7 } & 2 & 4 & 6 & 8 & 10 & 12 \\
\hline $\mathrm{m} 1$ & $6,08 \mathrm{c}$ & $13,25 \mathrm{~b}$ & $13,58 \mathrm{c}$ & $17,67 \mathrm{c}$ & $29,58 \mathrm{a}$ & $29,83 \mathrm{~b}$ \\
$\mathrm{~m} 2$ & $6,58 \mathrm{~b}$ & $11,58 \mathrm{c}$ & $15,33 \mathrm{~b}$ & $19,50 \mathrm{~b}$ & $27,42 \mathrm{~b}$ & $31,00 \mathrm{~b}$ \\
$\mathrm{~m} 3$ & $7,17 \mathrm{a}$ & $13,50 \mathrm{a}$ & $16,42 \mathrm{a}$ & $19,83 \mathrm{a}$ & $30,25 \mathrm{a}$ & $34,08 \mathrm{a}$
\end{tabular}

Keterangan : Angka-angka yang diikuti huruf yang sama menunjukkan tidak berbeda nyata pada uji BNT 5\%

Tabel 3. Rata-rata hari pertama berbunga (hari) pada perlakuan media tanam

\begin{tabular}{cc}
\hline Media tanam & Umur berbunga (hst) \\
\hline $\mathrm{m} 1$ & $84,42 \mathrm{c}$ \\
$\mathrm{m} 2$ & $75,75 \mathrm{a}$ \\
$\mathrm{m} 3$ & $78,08 \mathrm{~b}$ \\
\hline
\end{tabular}

Keterangan : Angka-angka yang diikuti huruf yang sama menunjukkan tidak berbeda nyata pada uji BNT 5\%

Tabel 4. Rata-rata diameter bunga $(\mathrm{mm})$ pada perlakuan media tanam

\begin{tabular}{cc}
\hline Media tanam & Diameter bunga $(\mathrm{mm})$ \\
\hline $\mathrm{m} 1$ & $65,51 \mathrm{c}$ \\
$\mathrm{m} 2$ & $71,15 \mathrm{a}$ \\
$\mathrm{m} 3$ & $69,89 \mathrm{~b}$ \\
\hline
\end{tabular}

Keterangan : Angka-angka yang diikuti huruf yang sama menunjukkan tidak berbeda nyata pada uji BNT 5\%

Tabel 5. Rata-rata berat bunga (gram) pada perlakuan media tanam

\begin{tabular}{cc}
\hline Media tanam & Berat bunga (gram) \\
\hline $\mathrm{m} 1$ & $43,82 \mathrm{c}$ \\
$\mathrm{m} 2$ & $53,65 \mathrm{a}$ \\
$\mathrm{m} 3$ & $48,71 \mathrm{~b}$ \\
\hline
\end{tabular}

Keterangan : Angka-angka yang diikuti huruf yang sama menunjukkan tidak berbeda nyata pada uji BNT 5\%

Hasil analisis sidik ragam menunjukkan bahwa pengaruh media tanam arang sekam + cocopeat berpengaruh sangat nyata pada jumlah daun dan tinggi tanaman. Menurut Prihmantoro dan Indriani (2003), Media tanam sangat penting diperhatikan dalam mendukung pertumbuhan tanaman. Media yang baik yaitu dapat memasok sebagian unsur-unsur hara yang dibutuhkan oleh tanaman. Sebagian besar unsur hara yang dibutuhkan tanaman dipasok melalui media tanaman. Selanjutnya diserap oleh perakaran dan digunakan untuk proses fisiologis tanaman. Tiap jenis media tanam mempunyai bobot dan porositas yang berbeda. Dalam memilih media sebaiknya dicari kombinasi media tanam yang tepat sesuai dengan jenis tanaman.

Menurut Ihsan (2013), kandungan hara yang terkandung dalam cocopeat yaitu unsur hara makro dan mikro yang dibutuhkan tanaman diantaranya adalah kalium, fosfor, kalsium, magnesium dan natrium. Cocopeat dapat menahan kandungan air dan unsur kimia pupuk serta menetralkan kemasaman tanah. Karena sifat tersebut, sehingga cocopeat dapat digunakan sebagai media yang baik untuk hasil tanaman salah satunya kecepatan berbunga dan diameter crop. Sedangkan arang sekam menurut Prihmantoro dan Yovita. (2001), arang sekam bisa berguna sebagai penyimpan sementara unsur hara dalam tanah jadi tak mudah tercuci 
oleh air, dan sangat mudah dilepaskan ketika diperlukan alias diambil oleh akar tanaman. Bisa dikatakan arang sekam berguna semacam zeolit. Arang sekam mempunyai peranan penting sebagai media tanam pengganti tanah. Arang sekam bersifat porous, ringan, tak kotor dan lumayan bisa menahan air. Arang sekam merupakan media tanam yang baik karena memiliki kandungan $\mathrm{SiO} 252 \%$ dan unsur $\mathrm{C}$ $31 \%$ serta komposisi lainnya seperti $\mathrm{Fe} 203$, $\mathrm{K} 2 \mathrm{O}, \mathrm{MgO}, \mathrm{CaO}, \mathrm{MnO}$ dan $\mathrm{Cu}$ dalam jumlah yang sangat sedikit. Unsur hara pada arang sekam antara lain nitrogen $(\mathrm{N}) 0.32 \%$, phosphat (P) $0.15 \%$, kalium (K) $0.31 \%$, calsium $(\mathrm{Ca})$ $0.96 \%$, Fe 180 ppm, Mn 80.4 ppm, Zn 14.10 ppm dan pH 8,5 - 9,0. Hal ini sesuai dengan penelitian yang dilakukan menunjukan hasil terbaik pada tinggi tanaman dan diameter dengan menggunakan media tanam arang sekam + cocopeat. Sedangkan dengan menggunakan media tanam cocopeat berpengaruh sangat nyata pada hari berbunga, diameter crop dan berat crop. Menurut Prihmantoro Indriani (2003), cocopeatdapat menyerap air dan Dapat menyimpan kandungun air dengan baik (nutrisi) sehingga dapat menjaga ketersediaan nutrisi untuk tanaman ketersediaan oksigen bagi akar sehingga dapat meningkatkan hasil pada tanaman. Ditambahkan Ihsan (2013), dapat menahan kandungan air dan unsur kimia pupuk serta dapat menetralkan keasaman tanah dan kandungan unsur hara yang dimiliki cocopeat, ternyata jumlah yang paling berlimpah adalah unsur K (kalium). Seperti yang telah kita ketahui bahwa kandungan (P) Fosfor dan (K) Kalium sangat dibutuhkan tanaman saat proses pembentukan buah serta peningkatan rasa untuk segala jenis buah. Karena sifat tersebut, sehingga cocopeat dapat digunakan sebagai media yang baik untuk pertumbuhan tanaman hortikultura dan media tanaman hydroponik.

\section{Pengaruh Sistem Hidroponik}

Tabel 6. Rata-rata tinggi tanaman $(\mathrm{cm})$ pada perlakuan sistem hidroponik

\begin{tabular}{ccccccc}
\hline \multirow{2}{*}{ Sistem hidroponik } & \multicolumn{7}{c}{ Umur tanaman $(\mathrm{mst})$} \\
\cline { 2 - 7 } & 2 & 4 & 6 & 8 & 10 & 12 \\
\hline $\mathrm{s} 1$ & $6,21 \mathrm{~b}$ & $17,23 \mathrm{c}$ & $20,98 \mathrm{c}$ & $25,88 \mathrm{~b}$ & $27,32 \mathrm{c}$ & $32,11 \mathrm{c}$ \\
$\mathrm{s} 2$ & $6,76 \mathrm{a}$ & $19,38 \mathrm{~b}$ & $23,11 \mathrm{a}$ & $28,87 \mathrm{a}$ & $33,67 \mathrm{a}$ & $32,81 \mathrm{a}$ \\
$\mathrm{s} 3$ & $4,72 \mathrm{c}$ & $20,98 \mathrm{a}$ & $22,62 \mathrm{~b}$ & $25,37 \mathrm{c}$ & $31,44 \mathrm{~b}$ & $33,24 \mathrm{~b}$ \\
\hline
\end{tabular}

Keterangan : Angka-angka yang diikuti huruf yang sama menunjukkan tidak berbeda nyata pada uji BNT 5\%

Tabel 7. Rata-rata jumlah daun (helai) pada perlakuan sistem hidroponik

\begin{tabular}{ccccccc}
\hline \multirow{2}{*}{ Sistem hidroponik } & \multicolumn{7}{c}{ Umur tanaman (mst) } \\
\cline { 2 - 7 } & 2 & 4 & 6 & 8 & 10 & 12 \\
\hline s1 & $6,00 \mathrm{c}$ & $12,17 \mathrm{c}$ & $15,33 \mathrm{~b}$ & $17,67 \mathrm{c}$ & $27,33 \mathrm{~b}$ & $28,83 \mathrm{c}$ \\
$\mathrm{s} 2$ & $7,00 \mathrm{a}$ & $12,92 \mathrm{~b}$ & $14,00 \mathrm{c}$ & $19,75 \mathrm{a}$ & $30,50 \mathrm{a}$ & $31,75 \mathrm{~b}$ \\
s3 & $6,83 \mathrm{~b}$ & $13,25 \mathrm{a}$ & $16,00 \mathrm{a}$ & $19,58 \mathrm{~b}$ & $29,42 \mathrm{a}$ & $34,33 \mathrm{a}$ \\
\hline
\end{tabular}

Keterangan : Angka-angka yang diikuti huruf yang sama menunjukkan tidak berbeda nyata pada uji BNT 5\%

Tabel 8. Rata-rata hari pertama berbunga (hari) pada perlakuan sistem hidroponik

\begin{tabular}{cc}
\hline Sistem hidroponik & Umur berbunga (hst) \\
\hline s1 & $64,05 \mathrm{~b}$ \\
s2 & $71,32 \mathrm{a}$ \\
s3 & $71,19 \mathrm{a}$ \\
\hline
\end{tabular}

Keterangan : Angka-angka yang diikuti huruf yang sama menunjukkan tidak berbeda nyata pada uji BNT 5\%

Hasil analisis sidik ragam menunjukkan bahwa sistem drip irigasi berpengaruh sangat nyata pada tinggi tanaman $12 \mathrm{MST}$, hari berbunga diameter crop dan berat crop. Keuntungan Drip irigasi menurut Haman,(2004), tidak terjadi kehilangan hara dari pupuk, efisiensi distribusi air tinggi, hanya daerah perakaran yang terbasahi, suplai air dapat diatur dengan baik dan pemupukan dapat dilakukan bersamaan dengan irigasi. Irigasi tetes merupakan sistem irigasi yang paling efisien karena air diberikan dengan debit yang kecil di sekitar tanaman. Pada sistem tersebut, 
kehilangan air dari sumber sampai lahan tidak ada sehingga efisiensi irigasi tetes dapat mencapai 90\% sampai 95\% (Haman dan Yeager, 2004), hal ini sesuai dengan penelitian yang dilakukan menunjukan hasil terbaik Dengan sistem drip irigasi lebih efektif.

Menurut Karsono (2013), bahwa dengan sistem drip irigasi Tanaman mendapat suplai air, oksigen, dan nutrisi secara periodik, Suplai oksigen lebih baik karena terbawa air pasang dan surut, Mempermudah perawatan karena tidak perlu melakukan penyiraman.

Soeseno (1985), dengan sistemwick system berpengaruh pada pertumbuhan tanaman karena tidak ada bagian-bagian yang bergerak. Dalam budidaya hidroponik hal yang perlu diperhatikan adalah larutan nutrisi. Larutan nutrisi merupakan sumber pasokan makanan.

\section{Pengaruh Interaksi Perlakuan}

Tabel 9. Rata-rata tinggi tanaman $(\mathrm{cm})$ pada perlakuan sistem hidroponik dan media tanam

\begin{tabular}{ccccccc}
\hline \multirow{2}{*}{ Interaksi perlakuan } & \multicolumn{7}{c}{ Umur tanaman $(\mathrm{mst})$} \\
\cline { 2 - 7 } & 2 & 4 & 6 & 8 & 10 & 12 \\
\hline $\mathrm{m} 1 \mathrm{~s} 1$ & $7,05 \mathrm{de}$ & 19,15 & $20,60 \mathrm{e}$ & $25,9 \mathrm{f}$ & $26,33 \mathrm{ef}$ & $33,05 \mathrm{ab}$ \\
$\mathrm{m} 1 \mathrm{~s} 2$ & $7,11 \mathrm{~d}$ & 19,68 & $20,10 \mathrm{f}$ & $27,6 \mathrm{bc}$ & $33,65 \mathrm{bc}$ & $33,75 \mathrm{ab}$ \\
$\mathrm{m} 1 \mathrm{~s} 3$ & $8,13 \mathrm{a}$ & 21,7 & $22,5 \mathrm{~cd}$ & $26,8 \mathrm{e}$ & $30,05 \mathrm{cde}$ & $33,63 \mathrm{a}$ \\
$\mathrm{m} 2 \mathrm{~s} 1$ & $6,43 \mathrm{f}$ & 16,48 & $22,73 \mathrm{c}$ & $27 \mathrm{de}$ & $30,83 \mathrm{~cd}$ & $32,13 \mathrm{~cd}$ \\
$\mathrm{~m} 2 \mathrm{~s} 2$ & $5,43 \mathrm{~g}$ & 20,55 & $22,38 \mathrm{~d}$ & $27,23 \mathrm{~cd}$ & $28,63 \mathrm{def}$ & $31,58 \mathrm{de}$ \\
$\mathrm{m} 2 \mathrm{~s} 3$ & $7,6 \mathrm{c}$ & 20,43 & $22,25 \mathrm{~d}$ & $21,38 \mathrm{~h}$ & $29,15 \mathrm{de}$ & $33,55 \mathrm{a}$ \\
$\mathrm{m} 3 \mathrm{~s} 1$ & $5,15 \mathrm{~h}$ & 16,05 & $19,6 \mathrm{~g}$ & $24,75 \mathrm{~g}$ & $24,8 \mathrm{f}$ & $31,15 \mathrm{e}$ \\
$\mathrm{m} 3 \mathrm{~s} 2$ & $7,75 \mathrm{~b}$ & 17,9 & $26,85 \mathrm{a}$ & $31,78 \mathrm{a}$ & $33,73 \mathrm{a}$ & $33,75 \mathrm{a}$ \\
$\mathrm{m} 3 \mathrm{~s} 3$ & $6,55 \mathrm{ef}$ & 18,8 & $23,1 \mathrm{~b}$ & $27,93 \mathrm{~b}$ & $31,13 \mathrm{bc}$ & $32,55 \mathrm{bc}$ \\
\hline
\end{tabular}

Keterangan : Angka-angka yang diikuti huruf yang sama menunjukkan tidak berbeda nyata pada uji BNT $5 \%$

Tabel 10. Rata-rata jumlah daun (helai) pada perlakuan sistem hidroponik dan media tanam

\begin{tabular}{ccccccc}
\hline \multirow{2}{*}{ Interaksi perlakuan } & \multicolumn{7}{c}{ Umur tanaman $(\mathrm{mst})$} \\
\cline { 2 - 7 } & 2 & 4 & 6 & 8 & 10 & 12 \\
\hline $\mathrm{m} 1 \mathrm{~s} 1$ & $6 \mathrm{f}$ & $12 \mathrm{e}$ & $14 \mathrm{~d}$ & $16,25 \mathrm{f}$ & 26,75 & $27 \mathrm{~d}$ \\
$\mathrm{~m} 1 \mathrm{~s} 2$ & $6,75 \mathrm{c}$ & $13,5 \mathrm{c}$ & $10,5 \mathrm{e}$ & $19,5 \mathrm{c}$ & 31,5 & $32,75 \mathrm{~b}$ \\
$\mathrm{~m} 1 \mathrm{~s} 3$ & $5,5 \mathrm{~h}$ & $14,25 \mathrm{a}$ & $16 \mathrm{bc}$ & $17,25 \mathrm{e}$ & 30,5 & $29,75 \mathrm{bcd}$ \\
$\mathrm{m} 2 \mathrm{~s} 1$ & $5,75 \mathrm{~g}$ & $12 \mathrm{e}$ & $15,75 \mathrm{c}$ & $19,5 \mathrm{c}$ & 26,25 & $30,5 \mathrm{bc}$ \\
$\mathrm{m} 2 \mathrm{~s} 2$ & $6,5 \mathrm{~d}$ & $11 \mathrm{~g}$ & $14,25 \mathrm{~d}$ & $18,5 \mathrm{~d}$ & 28,75 & $29,75 \mathrm{bcd}$ \\
$\mathrm{m} 2 \mathrm{~s} 3$ & $7,5 \mathrm{~b}$ & $11,75 \mathrm{f}$ & $16 \mathrm{bc}$ & $20,5 \mathrm{~b}$ & 27,25 & $32,75 \mathrm{~b}$ \\
$\mathrm{~m} 3 \mathrm{~s} 1$ & $6,25 \mathrm{e}$ & $12,5 \mathrm{~d}$ & $16,25 \mathrm{~b}$ & $17,25 \mathrm{e}$ & 29 & $29 \mathrm{~cd}$ \\
$\mathrm{~m} 3 \mathrm{~s} 2$ & $7,75 \mathrm{a}$ & $14,25 \mathrm{a}$ & $17 \mathrm{a}$ & $21,25 \mathrm{a}$ & 31,25 & $32,75 \mathrm{~b}$ \\
$\mathrm{~m} 3 \mathrm{~s} 3$ & $7,5 \mathrm{~b}$ & $13,75 \mathrm{~b}$ & $16 \mathrm{bc}$ & $21 \mathrm{a}$ & 30,5 & $40,5 \mathrm{a}$ \\
\hline
\end{tabular}

Keterangan: Angka-angka yang diikuti huruf yang sama menunjukkan tidak berbeda nyata pada uji BNT $5 \%$

Tabel 11. Rata-rata hari pertama berbunga (hari) pada perlakuan sistem hidroponik dan media tanam

\begin{tabular}{cc}
\hline Interaksi perlakuan & Umur tanaman (hst) \\
\hline m1s1 & $81,50 \mathrm{~d}$ \\
$\mathrm{~m} 1 \mathrm{~s} 2$ & $86,75 \mathrm{fg}$ \\
$\mathrm{m} 1 \mathrm{~s} 3$ & $85,00 \mathrm{e}$ \\
$\mathrm{m} 2 \mathrm{~s} 1$ & $68,00 \mathrm{a}$ \\
$\mathrm{m} 2 \mathrm{~s} 2$ & $73,25 \mathrm{~b}$ \\
$\mathrm{~m} 2 \mathrm{~s} 3$ & $86,00 \mathrm{ef}$ \\
$\mathrm{m} 3 \mathrm{~s} 1$ & $80,00 \mathrm{c}$ \\
$\mathrm{m} 3 \mathrm{~s} 2$ & $67,00 \mathrm{a}$ \\
$\mathrm{m} 3 \mathrm{~s} 3$ & $87,25 \mathrm{~g}$
\end{tabular}




\section{Keterangan : Angka-angka yang diikuti huruf yang sama menunjukkan tidak berbeda nyata pada uji BNT $5 \%$}

Tabel 12. Rata-rata diameter bunga $(\mathrm{mm})$ pada perlakuan sistem hidroponik dan media tanam

\begin{tabular}{cc}
\hline Interaksi perlakuan & Diameter bunga $(\mathrm{mm})$ \\
\hline m1s1 & $53,35 \mathrm{~d}$ \\
$\mathrm{~m} 1 \mathrm{~s} 2$ & $70,8 \mathrm{~b}$ \\
$\mathrm{~m} 1 \mathrm{~s} 3$ & $72,39 \mathrm{a}$ \\
$\mathrm{m} 2 \mathrm{~s} 1$ & $70,47 \mathrm{~b}$ \\
$\mathrm{~m} 2 \mathrm{~s} 2$ & $72,34 \mathrm{a}$ \\
$\mathrm{m} 2 \mathrm{~s} 3$ & $70,64 \mathrm{~b}$ \\
$\mathrm{~m} 3 \mathrm{~s} 1$ & $68,32 \mathrm{c}$ \\
$\mathrm{m} 3 \mathrm{~s} 2$ & $70,83 \mathrm{~b}$ \\
$\mathrm{~m} 3 \mathrm{~s} 3$ & $70,53 \mathrm{~b}$ \\
\hline
\end{tabular}

Keterangan : Angka-angka yang diikuti huruf yang sama menunjukkan tidak berbeda nyata pada uji BNT 5\%

Hasil analisis sidik ragam menunjukkan bahwa pengaruh interaksi sistem drip irigasi dan media tanam arang sekam + cocopeat berpengaruh sangat nyata pada tinggi tanaman, jumlah daun, hari berbunga, diameter crop dan berat crop. Dengan sistem drip irigasi dan media arang sekam + hidroton dapat meningkatkan pertumbuhan tinggi, jumlah daun, hari berbunga, diameter crop dan berat crop arang sekam dan cocopeat bisa berkegunaan sebagai penyimpan sementara unsur hara pada media jadi tak mudah tercuci oleh air, dan sangat mudah dilepaskan ketika diperlukan oleh akar tanaman. Menurut Wuryaningsih (1996), Arang sekam + cocopeat mengandung $\mathrm{N}$ $0,32 \%$, PO $15 \%$, KO $31 \%$, Ca 0,95\%, dan $\mathrm{Fe}$ 180 ppm, Mn 80 ppm, Zn 14,1 ppm dan PH 6,8. Karakteristik lain dari arang sekam + cocopeat adalah ringan, Sirkulasi udara tinggi, kapasitas menahan air tinggi, mengikat air, tidak mudah menggumpal.

\section{KESIMPULAN}

1. Pengaruh sistem hidroponik yang terbaik terhadap tinggi tanaman, jumlah daun, diameter crop, pada tanaman kembang kol dicapai oleh perlakuan s2 (Drip irigasi). Sedangkan untuk hari berbunga yang terbaik dicapai perlakuan s3 (wick system).

2. Perlakuan media tanam yang terbaik terhadap tinggi tanaman dan jumlah daun yang terbaik dicapai oleh m3 (Arang sekam + cocopeat)

\section{DAFTAR PUSTAKA}

Adoko dan Hendra. 2014. Bertanam Hidroponik Ala Paktani Hydrofarm PT AgroMedia Pustaka. Jakarta Selatan.
Media arang sekam + cocopeatunsur hara yang dimiliki jumlah yang paling berlimpah adalah unsur K (kalium). Seperti yang telah kita ketahui bahwa kandungan (P) Fosfor dan (K) Kalium sangat dibutuhkan tanaman saat proses pembentukan buah serta peningkatan rasa untuk segala jenis buah. Karena sifat tersebut, sehingga arang sekam + cocopeat dapat digunakan sebagai media yang baik untuk pertumbuhan tanaman hortikultura dan media tanaman hydroponikDitambahkan Anonim (2013),

Ditambah (Karsono, 2013)dengansistem yang baik sehingga dapat membantu meningkatkan pertumbuhan dan hasil dengansistem drip irigasi Tanaman mendapat suplai air, oksigen, dan nutrisi secara periodik, Suplai oksigen lebih baik, Mempermudah perawatan karena tidak perlu melakukan penyiraman.

sedangkan untuk hari berbunga, diameter crop dan berat crop pada tanaman kembang kol yang terbaik dicapai oleh $\mathrm{m} 2$ (cocopeat).

3. Interaksi sistem hidroponik dan media tanam (SxM) yang terbaik terhadap tinggi tanaman dan jumlah daun dicapai oleh s2m3 (Drip irigasi + arang sekam + cocopeat). Untuk hari berbunga yang terbaik dicapai oleh $\mathrm{s} 1 \mathrm{~m} 2$ (ebb and flow + cocopeat).

Anonim. 2013. Macam-macam Media Tanam. http://kangtoo.wordpress.com/ macammacam-media-tanam/. Diakses pada tanggal 8 Oktober 2013

Anonim. 2014a. Teknologi Budi Daya Tanaman Pangan.http://www.iptek.net.id/ind/teknologi 
_pangan/index.phd?id=20 Diakses pada tanggal 28 Maret 2014.

, 2014 . Budidaya Kubis Bunga. http://www.budidaya furniture.blogshot.com. Diakses pada tanggal 28 maret 2014. 2014'. Hidroponik Praktis. PT. Trubus Swadaya. Jakarta

$2014^{\mathrm{d}}$.

http://tanonmandiritaniorganik.blogspot.com/ 2012/08/budi daya kembang-kol_30.html

2014 ${ }^{\mathrm{e}}$ http://www.amazine.co/39146/kand ungan-gizi-12-manfaat-kesehatan-kembangkol/

2014 ${ }^{\mathrm{f}}$. kembang kol.

http://dispertan.kaltimprov.go.id/2014

Budiana dan Herwibowo. 2014. Hidroponik Sayuran Untuk Hobi \& Bisnis. Penebar Swadaya. Jakarta

Cahyono, B. 2003. Kubis Bunga dan Broccoli.Kanisius. Yogyakarta.

http://tanamanhidroponik.com eolite-sebagaimedia-tanaman-hidroponik. Diakses pada tanggal 25 Oktober 2013.
Ihsan, M. 2013. Manfaat Serbuk Cocopeat / Serbuk Sabut Kelapa. Jakarta

Karsono. 2013. Pengaruh Berbagai Media Terhadap Perkecambahan Matoa. http://Semadim.wordpress.com. Diakses pada tanggal 23 September 2013

Pracaya. 2000. Kol Alias Kubis. Penebar Swadaya. Jakarta

Prihmantoro, H. dan Y. H. Indriani. 2003. Hidroponik Sayuran Semusim untuk Hobi dan Bisnis. Penebar Swadaya. Jakarta.

Rukmana, R. 1994. Budidaya Kubis Bunga dan Broccoli. Kanisius. Yogyakarta.

Soeseno. 1985. Hidroponik Sayuran Semusim. Penebar Swadaya. Jakarta.

Suteja, M. 2002. Pupuk dan Cara Pemupukan. PT. Rineka Cipta. Jakarta

Tjahjadi, Nur. 1996. Hama dan Penyakit Tanaman. Kanisius. Yogyakarta.

Wuryaningsih, S. 1996. Pertumbuhan Beberapa Setek Melati pada Tiga Macam Media. Jurnal Penelitian Pertanian. 5(3):50-57. 